\title{
VERTICAL GARDEN : PENGHIJAUAN UNTUK MENDUKUNG SMART LIVING DI KOTA YOGYAKARTA
}

\author{
Aviana Vety Jayanti \\ Department of Government Affairs and Admnistration \\ Jusuf Kalla School of Government \\ Universitas Muhammadiyah Yogyakarta \\ Email: aviivety99@gmail.com \\ Eko Priyo Purnomo \\ Department of Government Affairs and Admnistration \\ Jusuf Kalla School of Government \\ Universitas Muhammadiyah Yogyakarta \\ Email: eko@umy.ac.id \\ Aulia Nurkasiwi \\ Department of Government Affairs and Admnistration \\ Jusuf Kalla School of Government \\ Universitas Muhammadiyah Yogyakarta \\ Email: aulianurkasiwi@gmail.com
}

\begin{abstract}
Increasingly dynamic city development without being accompanied by the provision of vacant land for reforesting has a negative impact on the environment. Increasing air quality and noise levels make a city have to prepare solutions to solve problems that have an impact on the environment of human life. The concept of vertical garden emerged as an alternative greening that can be applied in cities with a level of availability of narrow vacant land such as the city of Yogyakarta. The impact of applying this concept can overcome problems such as decreased air quality due to pollution. This study uses qualitative methods to describe how the effect of applying vertical gardens as an alternative to greening in supporting smart environments.
\end{abstract}

Keywords: Smart Environment, Vertical Garden, Environment;

\begin{abstract}
Abstrak: Pembangunan kota yang semakin dinamis tanpa diiringi dengan penyediaan lahan kosong untuk penghijauan menimbulkan dampak buruk bagi lingkungan. Kualitas udara dan tingkat kebisingan yang semakin meningkat membuat sebuah kota harus menyiapkan solusi sebagai penyelesaian masalah yang berdampak pada lingkungan kehidupan manusia. Konsep vertical garden muncul sebagai salah satu alternative penghijauan yang dapat diterapkan di kota dengan tingkat ketersediaan lahan kosong yang sempit seperti Kota Yogyakarta. Dampak dari penerapan konsep ini dapat mengatasi masalah seperti kualitas udara yang menurun akibat polusi. Penelitian ini menggunakan metode kualitatif untuk mendeskripsikan bagaimana pengaruh penerapan vertical garden sebagai alternatif penghijauan dalam menudukung smart environment.
\end{abstract}

Kata kunci: Smart Environment, Taman Mendatar, Lingkungan; 


\section{Pendahuluan}

Pertumbuhan dan perkembangan

Kota Yogyakarta saat ini cukup pesat. Akibat dari pertumbuhan kota yang tidak terkendali menyebabkan alih fungsi lahan menjadi lahan bangunan semakin meningkat sehingga Ruang Terbuka Hijau (RTH) menjadi berkurang. Dampak yang mungkin timbul adalah terjadi bencana kekeringan karena pembangunan dilakukan di derah resapan air. Hal itu tidak menjadi masalah besar ketika masih terdapat pohon atau tumbuhan yang dapat menyimpan air. Namun pada kenyataannya banyak aktivitas penebangan pohon dilakukan dalam proses pembangunan. Menyebabkan penahan air hilang sehingga air mudah menguap kemudian terjadi kekeringan. Dampak yang lebih besar adalah kerusakan hutan lindung dan kawasan hijau yang dapat menyebabkan global warming (pemanasan global). Lingkungan yang telah mengalami kerusakan menyebabkan tingkat kenyamanan kota menjadi berkurang

Salah satu solusi dalam menyelesaikan permasalahan tersebut yaitu dengan menerapkan konsep kota hijau. Berbagai upaya terus dilakukan Pemkot Jogja untuk menambah RTH. Standar kebutuhan Ruang Terbuka Hijau (RTH) di Kota Yogyakarta seharusnya $30 \%$ dari keseluruhan ruang. Terdiri dari 20\% RTH publik dan $10 \%$ RTH privat. Namun saat ini Ruang Terbuka Hijau di Kota Yogyakarta baru mencapai kurang lebih $18 \%$ dan lebih banyak digunakan untuk taman interaktif dan ruang terbuka layak anak. Sulitnya memperoleh lahan kosong di wilayah Kota Yogyakarta untuk dijadikan lokasi RTH merupakan kendala tersendiri bagi pemerintah kota.

Penelitian yang dilakukan oleh Amalia Ratnasari (2015), menunjukkan bahwa Ruang Terbuka Hijau di Kota Yogyakarta pada tahun 2015 masih jauh dari standar kebutuhan yang harus dipenuhi dalam rangka mewujudkan kota hijau. Area prioritas untuk dijadikan RTH mencapai $3,84 \%$. Terdiri dari area jalur hijau jalan $0,48 \%$, area sempadan sungai $2,89 \%$, dan lahan kosong seluas $0,47 \%$. Luas total RTH hanya mampu mencapai $21,62 \%$. Sedangkan pada tahun 2018, Wakil Wali Kota Yogyakarta, Heroe Poerwadi, menyebutkan bahwa ruang terbuka hijau (RTH) yang ada saat ini hanya seluas 6,09 kilometer persegi, atau 18,76\% dari total luas wilayah Kota Jogja yakni 32,5 kilometer persegi. Ruang tersebut terdiri atas RTH public sebesar $5,83 \%$ dan RTH privat $12,93 \%$.

Dalam proses penyediaan lahan untuk RTH tersebut, pemerintah kota tidak bisa begitu saja secara langsung melakukan transaksi dengan warga. Harus memenuhi 
prosedur seperti yang dikemukakan oleh Kepala Dinas Pertanahan dan Tata Ruang (Dispetarung) Kota Yogyakarta, Hari Setya Wacana, yaitu syarat keluasan lahan, lokasi, dan legalitas tanah. Selain itu, pembelian lahan sebagai RTH publik juga harus berdasarkan usulan warga. Dwi Ardianta Kurniawan, Peneliti Pusat Studi Transportasi dan Logistik (Pustral) UGM, mengatakan bahwa daerah bantaran sungai termasuk daerah relokasi, sehingga seharusnya penduduk yang tinggal di daerah tersebut direlokasi. Namun untuk melakukan relokasi juga perlu persiapan fasilitas seperti lahan pengganti sebagai pengganti hak masyarakat yang diambil.

Oleh karena itu, konsep smart city menjadi tantangan bagi setiap kota khususnya Yogyakarta dalam menemukan solusi untuk menyelesaikan permasalahan yang ada. Salah satunya dengan menerapkan konsep vertical garden. Penelitian ini bertujuan untuk menjelaskan bagaimana pengaruh vertical garden sebagai alternative penghijauan di kota dengan kondisi ruang terbuka yang sedikit seperti di Kota Yogyakarta. Manfaat penelitian ini dapat digunakan sebagai penyumbang ide alternatif baik bagi pemerintah atau masyarakat dalam meningkatkan penghijauan pada kota dengan tingkat ketersediaan lahan kosong yang sedikit.

\section{Studi Terdahulu}

Banyak studi yang telah dilakukan tentang penghijauan sebuah kota. Bermacam-macam strategi telah dilakukan baik melalui kebijakan pemerintah maupun melibatkan masyarakat secara langsung dalam pelaksanaannya melalui berbagai gerakan masyarakat. Salah satu strategi yang dapat dilakukan adalah menyusun lembaga untuk meningkatkan pengelolaan, memberdayakan masyarakat, serta merancang pengelolaan program penghijauan. Faktor-faktor yang menjadi pertimbangan perencanaan berkenaan dengan fungsi dan rancangan kawasan yang bersangkutan juga menentukan arah penghijauan pada kawasan belukar, lahan kosong dan area tepi danau ${ }^{1}$.

Kota yang masih memiliki ruang terbuka yang cukup dikelola dan dimanfaatkan menjadi taman untuk meningkatkan penghijauan kota. Dinas kebersihan dan pertamanan sebagai pihak pengelola ruang terbuka hijau telah menjalankan pengelolaan dan penambahan lahan baru untuk digunakan sebagai taman atau ruang terbuka hijau. Beberapa taman dikelola menjadi taman aktif yang dapat digunakan untuk area bermain anak-anak dengan pengelolaan berdasarkan kebijakan

\footnotetext{
${ }^{1}$ Firman, Saam Zulfan, Y. D. (2014). Model Penghijauan Danau Sri Bandar Kayangan, Kecamatan Rumbai Pesisir Kota Pekanbaru. Pusat Penelitian Lingkungan Hidup Universitas Riau, (1999), h. 167-177.
} 
RTH. Ketika ruang terbuka hijau yang telah disediakan mengalami kerusakan akibat tidak dikelola dengan maksimal, maka dapat diatasi dengan mendesain ulang terhadap taman yang melibatkan masyarakat secara langsung dalam penataannya. Penataan ulang dapat dilakukan pula dengan menambah fasilitas seperti bangku taman atau sarana olahraga, $70-80 \%$ dari luas ruang terbuka hijau yang tersedia ditanami tanaman, kemudian melakukan perawatan terhadap fasilitas-fasilitas serta tanaman-tanaman yang ada. ${ }^{2}$ (Ridwan \& Sulistyarso, 2018), (Priambodo, Kushandayani, \& Widayati, 2014), (Sembel \& Malik, 2015)

Ditemukan pula studi mengenai gerakan masyarakat untuk mendukung penghijauan dalam penelitian Pratiwi (2017), Irfan, Afifuddin, \& Miftahudin (2013), Sudibyo, Adib, \& Wijayanti (2013), Suyanto, Soetarto, Sumardjo et al (2015), dan Lailia (2014). Masyarakat telah mengimplementasikan gerakan menanam pohon secara gotong royong supaya lingkungan asri serta daya serap air meningkat sehingga mencegah banjir.

2 Adinata, B. L. (2016). Kota ( Studi Di Dinas Kebersihan Dan Pertamanan Kota Surabaya ) Management Strategies Management of Green Open Soaces Og the City Park ( Studies in the Department Cleanliness and Landscaping City of Surabaya). Jurnal Mahasiswa. h. 56
Memperbaiki perilaku masyarakat dengan tidak membuag sampah sembarangan agar lingkungan rapi dan bersih. Penanaman pohon dapat dilakukan dengan sistem budidaya, misalnya budidaya pohon melinjo di Kabupaten Batubara. Yang memiliki fungsi ganda yakni untuk penghijauan serta meningkatkan pendapatan masyarakat. Selain melibatkan masyarakat umum, penghijauan dapat dilakukan dengan melibatkan masyarakat secara spesifik seperti program "Green Jihad" yang digerakkan oleh remaja di Kota Solo melalui iklan layanan masyarakat peduli lingkungan. Disamping gerakan penanaman, masyarakat juga melakukan gerakan pengelolaan sampah melalui gerakan komunitas "green community" untuk mendukung kota hijau. Bentuk kegiatannya meliputi sosialisasi, termasuk sosialisasi Bank Sampah menggunakan bahasa daerah, pemberdayaan, dan paradigma pengelolaan sampah green waste. Mendaur ulang sampah, pembuatan IPAL sebagai pengganti penyiraman air, Menjadikan Kampung Wisata Lingkungan Tengah Kota, serta melakukan penyuluhan dalam paguyuban untuk lebih peduli terhadap lingkungan.

Budiman \& Sunan (2017) dan (2013) menyebutkan bahwa penanaman pohon disekitar daerah aliran sungai juga perlu. Tidak cukup hanya sekedar menanam saja namun juga disesuaikan dengan 
perencanaan, penyediaan, pemeliharaan, hingga pengawasan untuk mempertahankan keberadan hijauan kota yang terdapat di kawasan tanggul sungai. Pengelolaan sampah juga perlu diperhatikan untuk membantu sebuah kota mempertahankan kehijauannya. Sejalan dengan itu, peran pemerintah juga diperlukan dalam membuat kebijakan untuk mendukung kota hijau dalam mewujudkan smart city khususnya dalam bidang lingkungan. Salah satunya memasukkan salah satu kawasan hutan lindung menjadi RTH di Kota tersebut yang didalamnya dilarang melakukan pembangunan fisik untuk menjaga ekosistem seperti dalam studi Zuhaidha, Santoso, \& Maesaroh (2014). Dapat pula mengadakan program kerjasama antara dua negara dengan membandingkan penataan kota berwawasan lingkungan untuk mewujudkan green city. Sepertister city program yang dilakukan oleh Kota Kitakyushu di Jepang dengan Kota Surabaya di Indonesia ${ }^{3}$.

\section{Kerangka Teori}

Smart City

Bolivar (Caragliu dkk, 2011) mengungkapkan bahwa kota pintar dapat dikonseptualisasikan dengan cara yang

3 Nuralam, I. P. (2018). Peran Strategis Penerapan Konsep Sister City Dalam Menciptakan Surabaya Green-City. Journal of Applied Business Administration, 2(1), h. 144-151.

https://doi.org/10.30871/jaba.v2i1.807. berbeda, dari penggunaan intensif teknologi informasi dalam konteks perkotaan, untuk generasi layanan inovatif, kemampuan organisasi dan fisik infrastruktur. Singkatnya, kota pintar merupakan upaya untuk membuat setiap kota lebih pintar keduanya teknologi dan sosial; dari peningkatan kenyamanan, memfasilitasi mobilitas, menciptakan proses, efisiensi, menghemat energi, meningkatkan kualitas udara dan air, mengidentifikasi masalah dan menyelesaikannya dengan cepat pulih dengan cepat dari bencana, mengumpulkan data untuk membuat keputusan yang lebih baik, penggelaran sumber daya secara efektif dan berbagi data untuk memungkinkan kolaborasi lintas entitas dan domain.

Menurut Yang (2012), smart city merupakan kota yang meningkatkan aspek pemerintahan, ekonomi, kualitas hidup, lingkungan, sumber daya manusia, dan transportasi untuk menciptakan pembangunan ekonomi berkelanjutan dan kualitas hidup yang tinggi bagi warganya yang dilakukan melalui infrastruktur teknologi informasi dan komunikasi yang kuat. Sedangkan Griffinger dkk (2007) mendefinisikan smart city sebagai kota yang berorientasi pada masa depan dengan mengutamakan aspek pemerintahan, masyarakat, perekonomian, lingkungan, mobilitas, kehidupan. (Tim PSSR UGM, 2016). 
Chourabi et al. (2012), Gil-Garcia et al. (2014), dan Nam\&Pardo (2014) menyebutkan komponen-komponen yang perlu diperhatikan dalam menganalisis smart city, antara lain (Rachmawati \& Pertiwi, 2017) :

1. Pelayanan publik

2. Manajemen dan administrasi kota

3. Kebijakan dan pengaturan lembaga lainnya

4. Pemerintahan, keterlibatan dan kolaborasi

5. Sumber daya manusia dan kreativitas

6. Pengetahuan ekonomi dan lingkungan pro-bisnis

7. Infratruktur lingkungan dan kota yang dibangun

8. Keberlanjutan ekologis dan lingkungan alam

9. Teknologi Informasi dan Komunikasi

10. Data dan informasi. Giffinger et al. (2007)

mengemukakan bahwa terdapat 6 dimensi smart city untuk menilai kinerja sebuah kota sebagai kota pintar yang diterapkan dalam Proyek Uni Eropa

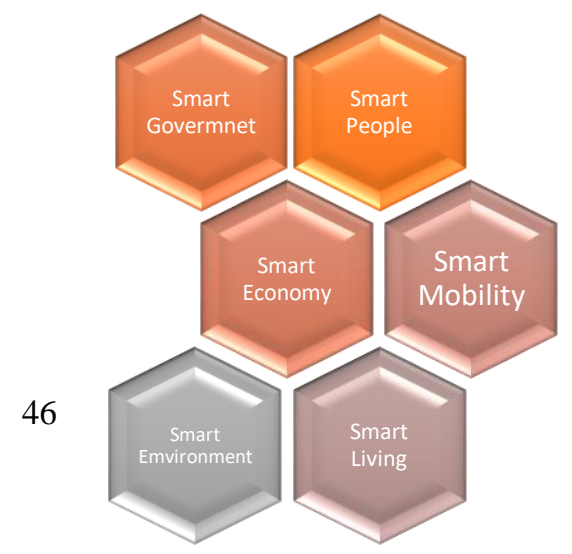

(Rachmawati \& Pertiwi, 2017).

Masing-masing dimensi smart city yang telah disebutkan di atas mempunyai indikator sebagai alat untuk mengukur penerapan smart city di 70 kota di Eropa. Dari 70 kota tersebut, ditemukan 3 kota besar yang menduduki peringkat tertinggi sebagai smart city, yakni Luxembourg, Aarhus dan Turku. Dimensi-dimensi yang telah disebutkan diatas, Cohen (2014) mengembangkan lagi ke dalam beberapa indikator penilaian sebagai berikut ${ }^{4}$ :

\begin{tabular}{|c|c|c|}
\hline Dimension & $\begin{array}{c}\text { Working } \\
\text { Area }\end{array}$ & Indicators \\
\hline Smart & Online & Online \\
\hline \multirow[t]{13}{*}{ Government } & \multirow[t]{5}{*}{ Services } & Procedures \\
\hline & & Electronic \\
\hline & & Benefits \\
\hline & & Payments \\
\hline & & Wifi Coverage \\
\hline & \multirow{7}{*}{$\begin{array}{c}\text { Infrastruct } \\
\text { ure }\end{array}$} & Broadband \\
\hline & & Sensor \\
\hline & & Coverage \\
\hline & & Integrated \\
\hline & & healt and \\
\hline & & safety \\
\hline & & operations \\
\hline & Open & Open Data \\
\hline
\end{tabular}

4 UGM, T. (2016). Road Map Kota Yogyakarta MEnuju Smart City. Jurnal Online Universitas Gajah Mada. 
Aviana Vety Jayanti, Eko Priyo Purnomo, dan Aulia Nurkasiwi Vertical Garden: Penghijauan Untuk Mendukung Smart Living Di Kota Yogyakarta

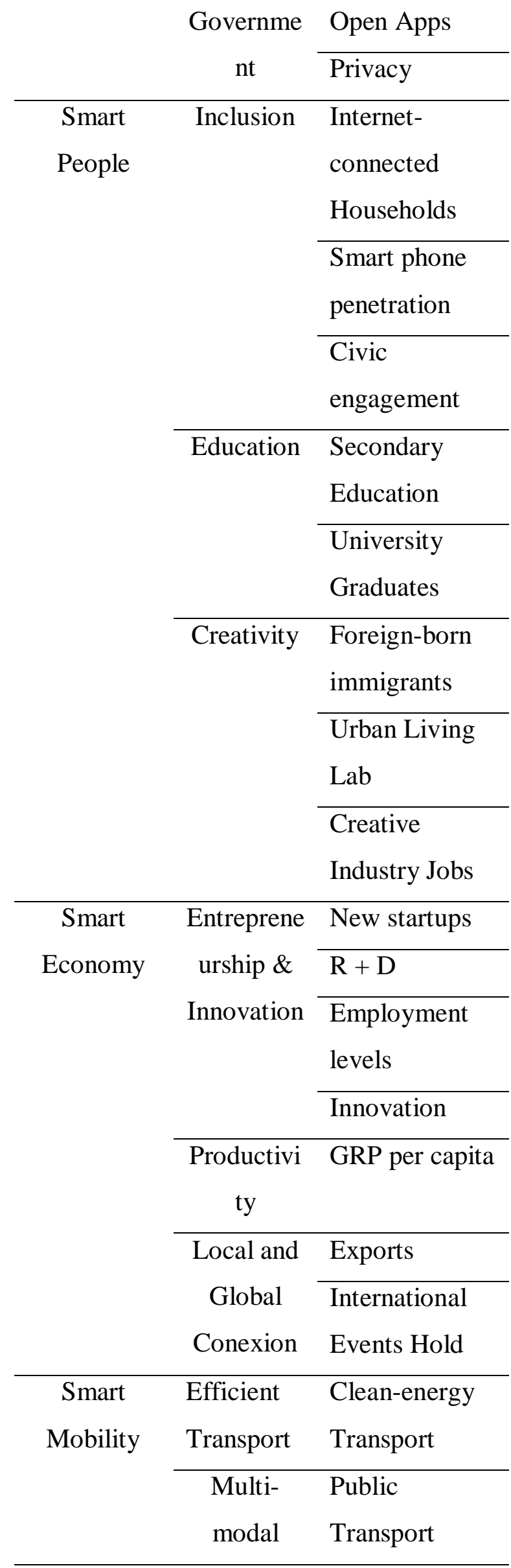

Access

\begin{tabular}{|c|c|c|}
\hline & Technolog & Smart cards \\
\hline & $\mathrm{y}$ & Access to real- \\
\hline & Infrastruct & time \\
\hline & ure & information \\
\hline Smart & Smart & Sustainability- \\
\hline Environmen & Buildings & certified \\
\hline $\mathrm{t}$ & & Buildings \\
\hline & & Smart homes \\
\hline & Resources & Energy \\
\hline & Managem & Carbon \\
\hline & ent & Footprint \\
\hline & & Air quality \\
\hline & & Waste \\
\hline & & Generation \\
\hline & & Water \\
\hline & & consumption \\
\hline & Sustainabl & Climate \\
\hline & e Urban & resilience \\
\hline & Planning & planning \\
\hline & & Density \\
\hline & & Green Space \\
\hline & & per capita \\
\hline Smart & Culture & Life \\
\hline Living & and Well- & Conditions \\
\hline & being & Gini Index \\
\hline & & Quality of life \\
\hline & & ranking \\
\hline & & Investment in \\
\hline & & Culture \\
\hline & Safety & Crime \\
\hline & & Smart Crime \\
\hline
\end{tabular}




\begin{tabular}{ll} 
& Prevention \\
\cline { 2 - 3 } Health & Single Health \\
& History \\
\cline { 2 - 2 } & Life \\
& Expectancy
\end{tabular}

Sumber : Giffinger (2007) dalam

UGM, T. P. (2016)

\section{Metode Penelitian}

Jenis penelitian ini adalah kualitatif. Menurut Maloeng (2005) dalam (Juhra, Lengkong, \& Dengo, 2018) penelitian kualitatif dengan deskriptif yaitu suatu metode penelitian untuk memahami fenomena yang terjadi dan dialami oleh subyek penelitian (baik perilaku, persepsi, tindakan atau yang lainnya) secara keseluruhan, yang kemudian dideskripsikan dengan kata-kata dan bahasa.

Teknik analisis data yang digunakan dalam penelitian ini adalah teknis analisis kualitatiArtinya, data yang diperoleh diolah secara sistematis, dengan cara mengumpulkan data dan fakta tentang kajian penelitian untuk kemudian digambarkan dalam bentuk penafsiran pada data yang diperoleh dalam penelitian kualitatif yaitu analisis model interaktif dengan tiga prosedur yaitu ( Moleong 2009; 15-20):

1. Reduksi Data. Pemilihan dan pemusatan perhatian pada penyederhanaan, pengabstrakan dan transformasi data kasar yang muncul dari catatan-catatan tertulis di lapangan.

2. Penyajian. Menyajikan sekumpulan informasi tersusun yang dapat memberikan kemungkinan adanya penarikan kesimpulan dan pengambilan tindakan. Penyajian data dalam penelitian ini dilakukan dengan cara menggunakan kumpulan kalimat.

3. Penarikan Kesimpulan. Menganalisa atau meninjau ulang pada catatan-catatan lapangan dan kebenarannya kekokohannya, serta kecocokannya makna dari data.

\section{Pembahasan}

Luas wilayah Kota Yogyakart saat ini mencapai 32,5 kilometer persegi. Ruang terbuka hijau (RTH) yang tersedia saat ini hanya seluas 6,09 kilometer persegi saja, atau 18,76 persen dari total luas wilayah Kota Yogyakarta. Terdiri atas Ruang Terbuka Hijau Publik sebesar 5,83\% dan Ruang Terbuka Hijau privat $12,93 \%$. Salah satu penyebabnya adalah pembangunan fisik yang semakin dinamis tanpa diimbangi dengan penyediaan lahan kosong untuk dijadikan sebagai Ruang Terbuka Hijau. Ruang terbuka hijau yang tidak memenuhi target menyebabkan penghijauan menjadi tidak maksimal. Tidak heran jika saat ini Kota Jogja menjadi panas dan tampak penuh 
dengan polusi. Sehingga konsep Vertical

Garden muncul sebagai salah satu alternatif penghijauan yang dapat diterapkan di lahan sempit untuk mewujudkan salah satu komponen smart city yaitu smart environment.

Taman Vertikal (Vertical Garden/Vertical Geenery)

Vertical garden atau vertical greenery menurut Blanc (2008) adalah tanaman yang disusun berbentuk vertical untuk keseimbangan lingkungan sehingga mampu menciptakan iklim mikro yang spesifik di sekitarnya. Vertical garden dapat digunakan sebagai ide untuk membuat sebuah lingkungan perkotaan menjadi tampak alami.

Manfaat konsep taman vertikal :

1. Lingkungan menjadi lebih indah dan alami.

2. Menciptakan ruang hijau di lahan terbatas.

3. Mengurangi panas dari luar dan polusi udara.

4. Membantu meredam kebisingan suara.

5. Meningkatkan produksi oksigen.

Komponen Vertical Garden Menurut Blanc (2008) :

1. Struktur Pendukung
Terdiri atas tiga bagian utama yaitu bingkai logam berfungsi memberi lapisan udara sebagai sistem isolasi efisien, lapisan PVC untuk membuat struktur menjadi tahan air, dan lapisan holding yang terbuat dari poliamida yang tahan korosi untuk meningkatkan kapilaritas air yang homogeny.

\section{Media Tanam}

Menggunakan media felt, yaitu bahan seperti kain terbuat dari bulu binatang sebagai tempat pegangan akar. Kriteria media tanam yang bisa digunakan pada model taman vertikal yaitu :

a. Tahan lama, tidak mudah lapuk, dan kokoh dalam menopang tanaman agar dapat tumbuh secara optimal.

b. Bersifat porous untuk mengalirkan kelebihan air serta dapat menciptakan rongga sehingga proses drainase dan aerasi berjalan dengan baik.

c. Dapat menyediakan unsur hara baik makro maupun mikro yang dibutuhkan oleh tanaman untuk kebutuhan nutrisi. Jenis media tanam yang dapat digunakan berdasarkan bahan pembentuknya.

d. Media tanam bahan organik, seperti pupuk kandang, arang, sabut kelapa, rumput laut, dan sebagainya.

e. Media tanam bahan anorganik, seperti kerikil, pasir, pecahan batu 
bata, tanah liat, spons, gabus, dan sebagainya.

Bobot dalam media tanam sangat perlu diperhatikan karena dapat mempengaruhi berat keseluruhan dari vertical garden sehingga dianjurkan untuk memilih bobot yang relative ringan. Tanaman yang dapat digunakan adalah tanaman yang memiliki akar adaptif dan biasa tumbuh menempel secara alami di beberapa tempat seperti pinggiran sungai, gua, air terjun, cekungan, hutan, dan tebing. Taman vertical menggunakan sistem irigasi melalui tabung plastic sederhana dan umumnya terbuat dari low-density polyurethane untuk mentoleransi pemuaian. Tabung atau pipa diletakkan mendatar di bagian atas taman dengan ukuran 1/2-inch (2-mm) lubang yang menembus setiap 4 inci $(10 \mathrm{~cm})$. Penyiraman dilakukan sebanyak 3-5 kali sehari menyesuaikan tinggi dari taman vertika tersebut.

Berdasarkan tingkat perawatannya terdapat 2 jenis Vertical Garden ${ }^{5}$, yaitu :

a. Green Facade

5 Ghoustanjiwani A.P, Rio Kusmara, \& Wahyu Yanuar. (2011). Teknologi Vertical Garden : Sustainable Design atau Hanya Sebuah Trend dalam Urban Life Style? Scan\#2: 2011, 2(Life Style and Architecture), h. 580. Retrieved from http://atmajayarchitecture.wordpress.com/
Green facade adalah permukaan yang ditumbuhi tumbuhan merambat yang tumbuh sendiri dan bukan merupakan media tanam, namun hanya menjadi media tumbuhan untuk merambat. Pada umumnya tanaman semacam ini tumbuh secara horizontal pada permukaan tanah lalu merambat secara vertical. Vertical garden jenis ini perawatannya lebih mudah karena tidak membutuhkan media maupun peralatan khusus untuk tumbuh.

\section{b. Living Wall}

Living wall dapat dikatakan sebagai pembaruan teknologi vertical garden dengan mengembangkan instalasi media panel tanam mendatar. Namun biaya pemasangan dan perawatan memang sedikit lebih mahal dibanding Green Facade.

Monica E. Kuhn dan Brad Bass (1999) dalam (Ghoustanjiwani A.P et al., 2011) mengemukakan bahwa vertical garden mempunyai peran untuk lingkungan, yaitu :

a. Meningkatkan kualitas udara menjadi lebih baik.

b. Melakukan penyaringan terhadap partikel kotor maupun pergerakan debu sehingga tidak memasuki ruang bangunan.

c. Mampu menyerap polusi.

\section{Penerapan Vertical Garden di Indonesia}


Aviana Vety Jayanti, Eko Priyo Purnomo, dan Aulia Nurkasiwi

Vertical Garden: Penghijauan Untuk Mendukung Smart Living Di Kota Yogyakarta

Teknologi vertical garden masih jarang di terapkan di Indonesia. Penyebabnya karena media tanam yang sebagian besar masih diperoleh dengan cara import sehingga biaya yang dibutuhkan relative lebih besar. Pada umumnya teknologi ini diterapkan di kota-kota besar dengan lahan terbuka yang sempit dan banyak transportasi dan industry yang banyak menghasilkan emisi karbondioksia (CO2) seperti Bandung dan Jakarta.

Bangunan-bangunan di Indonesia yang menerapkan vertical garden rupanya mayoritas bukan untuk mengatasi permasalahan lingkungan, melainkan lebih menjurus pada urban life style karena kebanyakan adalah bangunan komesil. Masyarakt dengan pendapatan yang rendah bekum cukup mampu menerapkan teknologi ini karena biaya yang relative mahal. Sedangkan di Kota Yogyakarta, bangunan yang menerapkan vertical garden adalah café-café yang umumnya hanya untuk menarik minat pelanggan saja. Belum menjurus pada penyelesaian masalah lingkungan.

\section{Pengaruh Vertical Garden Terhadap Lingkungan}

Sebagai salah satu alternatif penghijauan, vertical garden mempunyai beberapa pengaruh terhadap lingkungan, yaitu :

\section{a. Kualitas Udara}

Udara dengan kandungan oksigen yang banyak menjadi kebutuhan paling penting untuk kehidupan manusia. Pergerakan udara yang terus menerus merupakan syarat kenyamanan termal guna membuang panas yang berlebih dalam tubuh. Bangunan, langit-langit, dinding, dan lantai dapat membatasi pergerakan udara sehingga pergerakannya menjadi lamban dan meninmbulkan ketidaknyamanan. Sehingga vertical garden sangat diperlukan bagi bangunan untuk mengoptimalkan kecepatan pergerakan udara baik di luar maupun di dalam bangunan. Selain itu juga dapat berfungsi sebagai pengganti udara yang telah terkontaminasi suhu dan udara baru.

Kualitas udara di area pemukiman dan tepi jalan diukur setiap enam bulan sekali. Indikator pengujian kualitas udara menggunakan parameter fisik, antara lain :
a. Suhu
b. Kelembapan
c. Kecepatan angin
d. Tekanan udara
e. Tingkat kebisingan

Menurut Badan Meteorologi Klimatologi dan Geofisika (BMKG, 2018) kelembab-an udara merupakan besarnya 
kandungan uap air yang dikandung oleh udara dan mengalami perubahan berdasarkan perubahan suhu. Davis dkk., (2016) dalam (Lestari et al., 2019) menyebutkan bahwa pembuatan vertical garden mempunyai peran penting dalam menaikkan kelembaban udara dan menurunkan suhu dengan melakukan reduksi terhadap perpindahan panas antara bangunan dan lingkungan sekitar juga melindungi dari radiasi sinar matahari.

Hasil perhitungan yang dilakukan menggunakan metode ISPU dan pengukuran kebisingan ditemukan bahwa kualitas udara pada parameter $\mathrm{NO} 2, \mathrm{SO} 2$, dan $\mathrm{O} 3$ di tepi jalan raya dan pemukiman di Kota Yogyakarta dapat dikategorikan dalam keadaan baik. Sedangkan pengukuran kebisingan menggunakan sound level meter hasilnya lebih dari baku mutu. Kualitas udara yang telah diukur dalam keadaan baik ternyata mengalami perubahan seiring berjalannya waktu. Kota Yogyakarta yang semakin padat oleh kendaraan bermotor baik roda dua maupun roda empat menimbulkan polusi yang berakibat pada pencemaran udara, terlebih pada waktu liburan.

\section{b. Sebagai Pendingin Alami}

Vertical garden mampu mengurangi radiasi matahari dan memberikan efek pendingin alami bagi sebuah ruang bangunan. Udara cenderung berpindah dari daerah yang memiliki tekanan rendah ke tempat yang bertekanan tinggi sehingga memungkinkan terjadi aliran udara dalam sebuah bangunan. Kecepatan angin sekitar bangunan harus dikurangi, perangkat pelindung yang paling efektif adalah penghalang yang didirikan tegak lurus terhadap arah angin dan angin dari atas bangunan atau area luar bangunan yang akan dilindung. Taman vertikal dalam hal ini sebagai perangkat pelindung terhadap laju aliran udara panas pada luar bangunan.

\section{c. Pendukung Konsep Bangunan} Berkelanjutan (Garden Building)

Vertical garden juga berperan sebagai pendukung dari green building. Green guilding merupakan konsep bangunan berkelanjutan yang mempunyai persyaratan berupa indikator sistem perencanaan dan perancangan, lokasi, menggunakan prinsip hemat energy serta memiliki dampak positif untuk lingkungan, ekonomi, dan sosial. Green building bukan sebatas bangunan hijau saja, melainkan bangunan dengan perancangan berdasarkan aspek kualitas serta kenyamanan udara. Green building menggunakan bahan-bahan non toxic untuk meningkatkan kualitas udara dan meminimalisir penyakit akibat udara 
kotor seperti asma, alergi, maupun sick

building syndrome ${ }^{6}$.

\section{Penutup}

Vertical garden merupakan konsep tanaman yang disusun berbentuk vertical untuk keseimbangan lingkungan sehingga mampu menciptakan iklim mikro yang spesifik di sekitarnya. Dapat digunakan sebagai salah satu solusi alternative untuk meningkatkan penghijauan di area perkotaan yang memiliki lahan terbuka yang sempit. Beberapa manfaat dari vertical garden antara lain membuat lingkungan menjadi lebih indah dan alami, menciptakan ruang hijau di lahan terbatas, mengurangi panas dari luar dan polusi udara, membantu meredam kebisingan suara, serta meningkatkan produksi oksigen.

Beberapa kelemahan dari konsep vertical garden ini adalah masih jarang diterapkan di Indonesia yang tujuannya untuk penyelesaian masalah lingkungan. Selain itu biaya yang dikeluarkan juga relative lebih mahal. Namun ada solusi yang ditawarkan penulis yaitu masyarakat dapat membuat vertical garden sederhana menggunakan bahan bahan sederhana tanpa harus mengimport dengan catatan komponen-komponennya terpenuhi.

6 Sudarwani, M. (2012). Penerapan Green Architecture dan Green Building sebagai upaya pencapaian sustainable Architecture. Dinamika Sains, 10(24).

\section{Pustaka Acuan}

Ghoustanjiwani A.P, Rio Kusmara, \& Wahyu Yanuar. (2011). Teknologi Vertical Garden: Sustainable Design atau Hanya Sebuah Trend dalam Urban Life Style? Scan\#2: 2011, 2(Life Style and Architecture). Retrieved from http://atmajayarchitecture.wordpress.co $m /$

Lestari, W. P. Marpaung, R. T. Yolida, Pengaruh Vertical Garden Terhadap Suhu Ruangan Sebagai Lembar Kerja Materi Pemanasan Global. (Universitas Lampung: Bioterdidik, 2019)

Sudarwani, M. M. Penerapan Green Architecture dan Green Building sebagai upaya pencapaian sustainable Architecture. (Dinamika Sains, 2012)

Adinata, B. L. Kota ( Studi Di Dinas Kebersihan Dan Pertamanan Kota Surabaya ) Management Strategies Management of Green Open Soaces Og the City Park, ( Studies in the Department Cleanliness and Landscaping City of Surabaya: Jurnal Mahasiswa, 2016)

Budiman, A., \& Sunan, I. K. Gerakan Penghijauan Das Citarum Hulu Di Desa Cikoneng Kecamatan Cileunyi Kabupaten Bandung. (Bandung: Jurnal Aplikasi Ipteks Untuk Masyarakat, 2017)

Firman, Saam Zulfan, Y. D. (2014). Model Penghijauan Danau Sri Bandar Kayangan, Kecamatan Rumbai Pesisir Kota Pekanbaru. (Universitas Riau: Pusat Penelitian Lingkungan Hidup, 2014)

Irfan, P., Afifuddin, S., \& Miftahudin. Strategi Pembudidayaan Melinjo Sebagai Penghijauan dan Peningkatan Pendapatan Masyarakat di Kabupaten Batubara. Agrica (Sumatera Utara: Jurnal Agribisnis, 2013) 
AL-IMARAH: Jurnal Pemerintahan dan Politik Islam

Vol. 5, No. 1, 2020

Lailia, A. N. Hidup ( Studi Tentang Upaya Menciptakan Kampung Hijau Di Kelurahan Gundih Surabaya ). (Surabaya: Jurnal Politik Muda, 2014)

Nuralam, I. P. Peran Strategis Penerapan Konsep Sister City Dalam Menciptakan Surabaya Green-City. (Journal of Applied Business Administration, 2018) https://doi.org/10.30871/jaba.v2i1.807

Pratiwi, D. A. Pemberdayaan Masyarakat $R w 12$ Dalam Kegiatan Penghijauan Lingkungan Di Kavling Mandiri Kelurahan Sei Pelunggut. (Minda Baharu,2017) https://doi.org/10.33373/jmb.v1i1.1170

Priambodo, R. A., Kushandayani, \& Widayati, W. Pengelolaan Taman Menteri Soepeno Dalam Mendukung Kebijakan Ruang Terbuka Hijau Di Kota Semarang. (Semarang: Jurnal Ilmu Pemerintahan, 2014)

Allwinkle, Sam \& Cruickshank, Peter (2011). Creating Smart-er Cities: An Overview. Journal of Urban Technology, Vol. 18, No. 2, April 2011, 1-16. Routledge.

Ridwan, A., \& Sulistyarso, H. (2018). Strategi Peningkatan Efektivitas Ruang Terbuka Hijau Di Perumahan Wisma Gunung Anyar Surabaya. Jurnal Teknik, 7(1).

Rubiantoro, E. A., \& Haryanto, R. Bentuk Keterlibatan Masyarakat dalam Upaya Penghijauan pada Kawasan Hunian Padat di Kelurahan Serengan - Kota Surakarta. (Jurnal Pembangunan Wilayah \& Kota, 2013)

Sembel, A. S., \& Malik, A. A. M. (2015). Peningkatan Kualitas Ruang Terbuka Hijau Melalui Pembangunan Taman Pkk Di Kecamatan Kalawat. Media Matrasain, 12(3).

Sudibyo, G. A., Adib, A., \& Wijayanti, A. Program Green Jihad untuk Remaja di
Kota Solo. (Jurnal DKV Adiwarna, 2013)

Ratnasari, A., Sitorus, S. R., \& Tjahjono, B. (2015). Perencanaan Kota Hijau Yogyakarta Berdasarkan Penggunaan Lahan Dan Kecukupan Rth. Tataloka, 17(4).

Suyanto, E. Soetarto, E. Sumardjo, S. \& Hardjomidjojo, H. Model Kebijakan Pengelolaan Sampah Berbasis Partisipasi Green Community Mendukung Kota Hijau. MIMBAR, (Jurnal Sosial Dan Pembangunan, 2015) 31(1),

Zuhaidha, S. A. Santoso, R. S. \& Maesaroh. Perencanaan Strategi Pengembangan Ruang Terbuka Hijau Kota Semarang (Studi Kasus: Hutan Wisata Tinjomoyo). (Journal of Public Policy, 2014)

Griffinger, R., dkk (2007). Smart cities Ranking of European medium-sized cities. Final report October

Hasanah, H. (2017). TEKNIK-TEKNIK OBSERVASI (Sebuah Alternatif Metode Pengumpulan Data Kualitatif Ilmu-Ilmu Sosial). At-Taqaddum, $8(1)$.

Juhra, A., Lengkong, F. D. \& Dengo, S. (2018). Evaluasi Kebijakan Pengelolaan Persampahan Di Kota Manado. 4(56).

Nilamsari, N. (2014). Memahami Studi Dokumen Dalam Penelitian Kualitatif.

UGM, T. (2016). Road Map Kota Yogyakarta MEnuju Smart City. Jurnal Online Universitas Gajah Mada.

Writer, N. (2017, Juli 30). Jogja Sulit Wujudkan Aturan 30\% Ruang Terbuka Hijau. Dipetik 20 Desember, 2019, dari Semarang: https://semarang.bisnis.com/read/201 